for the semeiology and pathology of the ear. liut no credit was given to it for any curative power, which is the part which most interests those who physically and morally suffer from ear troubles. But to-day, thanks to the advancement of surgical studies, such a depreciatory remark is no longer possible, and in our department we obtain results which are certainly not less satisfactory than those secured in any other branch of medicine or surgery. The titles of many of the communications announced in the programme show the tendency of otology, and provided we do not carry surgical treatment to exaggration-as Lange of Copenhagen has justly remarked-I believe that this impulse will impart still greater progress to our specialty. If we should succed in contributing to this, we will be content with our work. With the hope that this will be realized, I am pleased to declare in the name of Ilis Majesty Humbert, King of Italy, that the Fifth International Congress of ()tology: is now open.

St. Clair Thomson (Trons.)

\title{
THE FIFTH INTERNATIONAL CONGRESS OF OTOLOGY.
}

Held at Florence, September 23rd to 26th, IS95.

Reported by Dr. Dundas GRAML:

THE Inaugural Meeting was held in the forenoon of Monday, September $23 \mathrm{rd}$, in the Aula Maxima of the Institute for Higher Studies. Prof. Grazzi, President of the Organizing Committee, occupied the chair, and he, as well as several representatives of the authorities, offercd a gracious wclcome to the Members of the Congress.

Prof. Grazzl was elected to the presidency of the Congress by acclamation, and delivered an eloquent address, in which he referred feclingly to the gaps which death had made in the ranks of otology, including, among others, Sapolini, Troeltsch, Calmettes and Moos. The eulogy on the last he left to Prof. Politzer. (Vitce p. Sof.)

Prof. Politzer, of Vienna, then pronouncerl a touching panegyric on the late Prof. Moos, of Heidelberg. Ile referred to his carly struggles, his untiring industry, his profound knowledge of seneral pathology, which pervaded his otological work and stamped it as having a value quite its own, the simplicity of his life, his secret beneficence and his devotion to his labours even when he knew his days were numbered. (Vide p. 8oz.)

The ordinary meetings were presided over, at the invitation of the President, by Profs. Politzer, Kirchner, Pritchard, and Drs. (iclle, Moure, Delstanche and Morpurgo.

I Many of the papers, of which merely the outlines are given in this report, will be published in the JOURNAr. OF LARYNGOLOGY in greater detail or in full. 


\section{Monday, September 23rd. Afternoon Meeting.}

Prof. GrazzI in the Chair.

A discussion on General Constitutional Treatment in Diseases of the Ear was opened by Dr. Gellé (Paris).

He pointed out that often the most important information the aurist could give was that the ear was quite normal, and that the physician must look elsewhere for the cause of constitutional disturbances, though in many instances he could trace them to disease of that organ. Of the acute forms of aural disease, he referred first to those occurring in the course of the eruptive or other fevers, recommending careful nasopharyngeal treatment as the best means for their prevention, and in particular Guye's method of nasal irrigation, the soda-water syphon douche, and, if necessary, the removal of tonsils. Deaf-mutism, he thought, might be at times prevented by prophylactic specific treatment of the mother during gestation, and by attention to the auditory organs in the infant. He alluded to the influence of intestinal antise sis practised by means of calomel, naphthol, salol and other means in preventing the multiplication of pathogenic microbes and the occurrence of septic infection, and directed attention also to the hygiene of the mouth. In acute otitis in general he administered sulphate of quinine, but when it arose from influenza he preferred antipyrin, and in gouty otitis the well-tried anti-arthritic remedies. He had hopes of advantage accruing from the application of serum therapeutics in infective diseases of the organs of hearing. In chronic otorrhœa he advocated more frequent recourse to antisyphilitic treatment, and attached great importance to general treatment in gouty, diabetic and tubercular subjects, believing in a future for serum treatment in the last. The removal of causes of weakness, such as prolonged suckling, was of urgent importance. The early administration of pilocarpin in sudden deafness was strongly advocated. Hypnotism, though occasionally of value in slight cases of functional deafness, had never proved of value in severe ones, and electricity was of value in a small sphere.

There was no further discussion on Dr. Gelle's exhaustive paper.

Dr. Yersand Arslain (Padua). On Adenoid Vegetations.

Dr. ARSLAN attached great importance to the diagnostic value of posterior rhinoscopy. In operating he employed the curette and the finger-nail, and invariably during anæsthesia by bromide of ethyl.

The discussion was continued by Drs. CORRADI, GorIS, Gradenigo, PRITCHARD, BABER, and others.

Dr. HELME protested against the employment of the finger-nail as liable to convey septic organisms.

Dr. MOURE held that the finger could be sterilized for this operation as well as for any other serious surgical proceeding such as a laparotomy.

Dr. DUNDAS GRANT operated under nitrous oxide on account of its 


\section{Rhinology, and Otology.}

safety, and in order to attain the necessary degrec of rapidity, he was accustomed to commence by scraping with his finger-nail, stcrilized by means of lysal and then alcohol, so as to judge at the same time of the extent, nature and situation of the growths, and select the instrument suitable for concluding the operation, namely, Gottstein's or Delstanche's curette when the back of the pharynx was the site of the growths, and Schech's or Quinlan's forceps in case of the vault being mainly involved.

Dr. OKUnefF (Russia). The use of Auscultation for the purpose of detecting Sclerotic Conditions of the Mastoid J'rocess.

A vibrating tuning-fork was placed on the parietal bone, and the chest-piece of a flexible stethoscope was applied to various points in the mastoid region. Over the sclerotic parts the sound was heard "higher," that is, with greater intensity.

Dr. Coosemans (Brussels!. On a Case of Cornu Cutaneum Auricula.

The patient was serenty-one years of age, and presented himself for treatment of a growth on his auriclc. This had commenced about a year previously, and had developed with greater rapidity after he had several times remored it with his nail, this cansing a little hir morrhage each time. It was completely remored by operation.

Prof. Aroledo (Milan). On the Results of Intra-tympanic Opcrations for Deafness following Suppuratiz'e Median Otitis.

He had found improvement in audition follow extraction of the malleus and incus with the addition of medication with pilocarpin to favour absorption.

Tuesday, September 24th. Morning Meeting.

Irof. Politzer in the Chair.

DISCUSSION ON JROF. AYOLIIDO'S PAPER.

Prof. FERRERI thought other factors might be at work and urged the employment of the caustic treatment, for which he is so powerful an advocate.

Dr. MORPURGo (Trieste) inculcated the need for the greatest caution for fear of bringing back the discharge or of injuring the facial nerve, especially in view of the fact that the otorrheca could often be checked without operation.

Dr. Gellé (Paris), remembering how many cases were kept up by intra-mastoid suppuration, advocated an early recourse to trepanation of the part.

Prof. GRadenigo (Turin) was strongly in favour of extraction of the ossicles.

Dr. Dundas GRANT (London) asked I)r. Cellé whether he could in all cases detect the presencc of intra-mastoid suppuration. so as to justify 
opening the apophysis without previously trying the effect of the less serious operation of removal of the ossicles, which was so much facilitated by the use of Dr. Delstanche's extractor. Dr. Grant thought there were many simple operations of great value, apart from the classical removal of ossicles. He had, for example, seen great amelioration, both as regards hearing and discharge, follow the section of a tight band running backwards from the short process of the malleus, and serving to retain small cholesteatomatous masses, and to hamper the movements of the stapes.

Dr. GeLLÉ replied that the views he had expressed were the outcome of his observation and experience, and he believed that in cases of persistent suppuration much time was often saved by prompt recourse to the mastoid operation.

Dr. MOURE (Bordeaux) advocated the removal of ossicles before the mastoid was trephined.

Dr. ARSLAN (Padua), like Prof. Ferreri, believed in a more thorough use of the caustic treatment, especially by means of chromic acid.

Prof. Delstanche considered a conservative caustic treatment of the utmost value, and he employed chloride of zinc in the deliquescent state. As a rule he removed the malleus, and afterwards employed chloride of zinc.

Prof. FERRERI considered the application of zinc more painful than that of silver.

Prof. PRITCHARD (London) spoke in praise of Prof. Delstanche's instrument, with which the malleus could be removed by the sense of touch alone, unaided by that of vision.

Dr. DÉLIE (Ypres) recommended the use of a fifty per cent. solution of lactic acid as the best caustic.

Prof. Politzer wished it to be distinctly understood that he had never advocated the use of pilocarpin to promote the absorption of adhesions, but only for labyrinthine disease. He considered surgical intervention on the inner wall of the tympanum most important, in view of the frequency of adhesions between the branches of the stapes and the sides of the niche for the oval window, some of which were physiological, so that only the head, and not the branches, could be seen. It was then advisable to make a horizontal cut below the stapes. If the incus was wanting, an incision should be made above also. The results of these incisions were sometimes permanent, in spite of the reunion of the severed bands, just as was seen after the performance of tenotomy of the tendo Achillis. Excision of the ossicles was not to be undertaken with a view to the improvement of audition; it sometimes had the opposite effect. He advocated in suitable cases the operation of severance of such posterior bands as referred to by Dr. Grant, and also of anterior bands. When the tip of the manubrium was tied down by adhesions of the promontory, he liberated it by incisions round it. If these operations failed to produce relief of subjective symptoms (tinnitus, vertigo, etc.), he then removed the malleus, so as to do away with the action of the tensor tympani in driving the stapes into the vestibule. Above all things, it was important to test the degree of fixation of the various parts by means of Siegel's exhausting speculum. 
Prof. Avolsio replied that it was only in bilateral cases that he operated with any idea of improving the hean ing. As reyards danger to the facial nerve, no injury to it had taken place in two cases in which he had removed the incus.

\section{Prof. Gradexigu (Turin). On Internal Treatment in Cases of Otitis Interna.}

Attention was drawn to the fact that some were acquired and some hereditary. In some there was actual clisease in the parents, in others only in near relatives. 'Too little attention was usually directed to the organism. In syphilitic cases, if not too late, specific treatment was to be carried out, and especially intra-muscular injections of perchloricle of mercury. In those cases in which the condition was secondary to sclerosis of the middle ear, the results were not grood. They were diathetic, not infectious, and treatment was to be directed mainly towards the condition of the naso-pharynx and the tendency to catarrh. The recognition of the gouty and rheumatic elements was insisted on.

Dr. MORPURGo insisted on the necessity of experience in general medical practice on the part of the specialist. Ile considered it often very difficult to diagnose the rheumatic diathesis.

Mr. CREsswell B.ABER (Brighton) held that in labyrinthine cases pilocarpin should be tried, but that if, after three or four injections, no improvement took place it should be discontinued. In acute cases it was necessary to give it a full trial, the patient being informed as to the doubtfulness of definite benefit accruing. In some cases small doses of iodide of potassium werc advisable. He narrated a case in which deafness accompanying myxœedema yiclded to thyroid treatment.

Dr. MOURE (Bordeaux) referred to the injurious influence of glycosuria. It did not debar operation, but called for appropriate clietetic and medicinal treatment before, during, and after.

Dr. RUTTEN recommended the administration of perchloride of mercury in the form of a nasal spray of the strength of one per thousand, along with the internal administration of iodide of potassium.

Dr. DUND.s GRANT insisted on a more careful diagnosis of the different forms of nerve-deafness. In particular he considered it most important to recognize nerve-deafness due to extreme debility. In such cases pilocarpin should be scrupulously avoided as only likely to debilitate the patient still more, and bring an otherwise valuable drug into disrepute. He found strychnine in large doses of the utmost value. $\mathrm{He}$ could confirm from his own experience Mr. Cresswell Baber's observations with regard to myxodema. Again, the recognition of gout and of Bright's disease was most important.

Dr. CoRRado CoRradi (Verona) pleaded for a more prolonged trial of pilocarpin.

Dr. Déle (Ypres) stated that in the form of Vin Nourry he could give larser doses of iodine without disturbance than in any other form.

Dr. Geiles said the same for the iodo-tannic syrup, but that it had to be well manufactured. It did not cattse iodism, and did not colorize starch. 
Dr. MADEUF corroborated this. If it colorized starch it was not good. When heated it ought to do so.

Prof. GRADENIGO, in replying, stated that his intention was not to make local treatment subsidiary, but to accentuate the movement in the direction of greater attention to general treatment, in view of the prevailing tendency to depend exclusively on local measures.

Dr. Brieger (Breslau). On Primary Ostitis of the Mastoid Process.

This occasionally occurred as a primary osteo-myelitis, and could only be distinguished from ordinary mastoiditis by the extreme rapidity of the destruction of bone. Secondary ostitis might be of typhoid or tuberculous origin. He thought the latter less common than was generally supposed.

Tuestay, September 24th. Afternoon Meeting.

Dr. GELLÉ in the Chair.

\section{Dr. Corrado Corradi (Verona). On Traumatic Perforations of the Tympanic Membrane.}

They might occur indirectly from blows on the head, with or without fracture of the skull, and were then generally situated at the periphery. When caused by direct compression of air in the meatus he found them to run downwards and backwards from the tip of the manubrium. He was unable to produce rupture of the membrane in the cadaver by heavy blows, but he thought that it occurred more readily in the living subject, owing to tension induced by contraction of the tensor tympani. Tension might be due to narrowing of the Eustachian tubes and the drum might be weakened by cicatrization. He narrated three cases.

Dr. GELLÉ (Paris) described a case of bilateral rupture from flat-hand blows given in play on the two ears simultaneously.

Prof. Politzer drew attention to two points in the diagnosis of traumatic perforation: ( 1 ) the presence of blood on the edges of the tear, (2) the full and free passage of air by Valsalva's method,

\section{Prof. Ferreri (Rome). On Senile Changes in the Middle Ear.}

$\mathrm{He}$ thought there was an undue tendency to attribute senile defects of hearing to labyrinthine change. He found more frequently the middle ear affected, and in particular the ossicular articulations.

Prof. GRADENIGO thought a continuance of such inquiries necessary.

Prof. Politzer reminded the congress of his anatomical investigations, showing disease of the labyrinthine capsule and anchylosis of the stapes.

Prof. Masini (Genoa) pointed out that Prof. Politzer's investigations were on cases of severe deafness, whereas Profs. Ferreri and Gradenigo's remarks applied to old men with normal hearing.

Dr. GELLÉ insisted on the recognition of the influence of senile degeneration of the nervous system, especially as regards the cerebral 


\section{Rhinology, and Otology.}

functions, and mentioned a case in which under this influence complete deafness had ensued without there being any lcsion of the auditory apparatus.

Dr. BAR (Nice). Aural Compliation of the (storation for Adenoids.

In a case of operation carried out with all care and antiscptic precaution there occurred three days later pain and constitutional disturbance, followed in two days by a purulent discharge. The incisure of Santorini were seen to be red. Irrigation of pheno-salyl, six per milligramme, were employed. By posterior rhinoscopy it was proved that there was no wound of the Eustachian tube. Possibly the otitis was to be attributed to the nasal douches employed. IIe referred, however, to Ziem's experiments, which proved that fluid could not be forced into the tympanum unless there was a counter-openin's in the membrane. [He omitted to add Ziem's further observation that this rule did not apply to liquids mixed with air in a sort of froth, on which account $Z$ iem recommended an air-tight nozzle for the clouche.-D.G.]

Mr. BABER (Brighton) mentioned the danger of using a nasal douche if the opposite notril was blocked by a deviation of the septum.

Dr. C. Delstanche (Brussels). Rimaris on the Employment of Liquid Vaseline in the Treatment of Affections of the Midlle Ear.

Since employing these in acute cascs he had become less and less in a hurry to perform paracentesis. Prof. Habermann had taken up the method, employing up to fifty centigrammes at at time. (Jut of thirty cases, this otologist had noted great improvement in twenty-two, tinnitus relicred in eighteen, vertigo much diminished in nine. The treatment was inclicated in serous, not in sclerotic, catarrh. Ile quoted Politer as considering massive injections of vaseline quite innocuous. Ife introduced the liquid vaseline through a catheter by means of a well-fitting syringe, and followed this up by an air-douche. The vaseline had to be chemically pure or sterilized by boiling. He did not consicler the addlition of iodoform necessary, but when added there was no need for it to be dissolved in ether. To objectors he stated that it had been proved that liquids could be driven into the tympanum (without counter-opening) if they were mixed with air.

Dr. SUNE y MoList (Barcelona) valued the method highly.

Dr. SECRETAN (Lausanne) thought the quantity of fluid injected should be very limited.

Dr. Dundas Grant (London) said the had found the mothod surprisingly beneficial, as had also his fellow-countryman, Dr. Adolph Bronner. Dr. Grant employed it in the manner described by Dr. Delstanche-went still further in driving it into the tympanum through a Weber-Liel's intra-tympanic catheter so as forcibly to break down certain adhesions. As regards so-called sclerosis of the middle ear as a contra-indication, there were certain cases in which the diagnosis of sclerotic otitis was perfectly clear and the patient should be spared all treatment, and there were others of equally unmistakable exudative otitis in which active treatment was imperatively called for. There were, however, many cases of an intermediate class where ireatment was 
experimentally justifiable, and the treatment of all others which deserved the best trial was that introduced to us by Dr. Delstanche.

Dr. Helye (Paris) asked if it was meant that this treatment was a substitute for paracentesis.

Dr. BRIEGER (Breslau) said there was no need to sterilize the vaseline. Reaction was only produced by traumatism or excess in the quantity of liquid. liquid.

Dr. MADEUF (Paris) employed solid vaseline in preference to the

Prof. Politzer said a case of anchylosis of the stapes had been reported as having been cured by this method. He thought it necessary to distinguish sclerosis more accurately, and he admitted the beneficial effects of the treatment in non-sclerotic cases.

Dr. Delstanche did not say this treatment was to take the place of paracentesis, he only stated that since he had adopted it he had taken to postponing paracentesis longer and longer. He gave up solic! vaseline on account of its inconvenience as soon as liquid vaseline came into use.

Dr. MCNaughton Jones (London). On the Relation of Turbinal Hypertrophy to Deafness, with special reference to the Operation of Turbinotomy.

The writer advised the use of this operation in selected cases, but protested against its indiscriminate practice in view of its limited usefulness, the risk from hæmorrhage, the possibility of septic disturbance, and the damage to the organism accruing from the removal of an organ having important physiological functions. In 300 cases of aural disease, 23I had no turbinal hypertrophy or nasal obstruction of any consequence. He attributed the turbinal hypertrophy in the remainder to the naso-pharyngeal catarrh, which was at the same time the cause of the concomitant aural disease. When once the turbinal had got so enlarged as to obstruct nasal respiration, he thought it became a further source of danger to the ear. In by far the majority of cases he considered the galvano-cautery, caustics and astringents as sufficient, especially if the treatment was followed up by the use of bougies, of which Dr. Jones showed some very smooth pliable forms. When these means were unavailing turbinotomy was indicated, but this could occur in relatively a very small proportion of aural cases.

Prof. GRADENIGO asked what kind of instrument was employed.

Dr. MCNalghton Jones promised to exhibit it the following day.

[The instrument shown was not the ring-knife or "spoke-shave" devised by Mr. Carmalt Jones, and so well known, but a sort of guillotine, very much like the French tonsillotome, but with grasping blades instead of a fork, and adapted to fit the turbinal. Dr. McNaughton Jones said it removed only the soft parts.-D. G.]

Dr. DUNDAS GRANT said he had performed the operation in a number of cases, though not nearly so often as his colleague, Mr. Carmalt Jones, to whom we were indebted for a very handy modification of an instrument employed by Mr. Spencer Watson. He had had no injurious effects, but he felt that there was a great temptation to make 
too frequent use of it. In regard to the use of the operation on account of cleafness, he thought a grood rule was to perform it only if it was called for on account of nasal obstruction, apart from the deafness. There was every reason to believe that in congestion of the middle or even of the internal ear bleeding from the turbinal effected a beneficial depletion. He regretted that Prof. Cozcolini was not present to give the results of his experiments on "nasal manometry in relation to manometry of the ear," from which important indications concernings nasal operations for aural disease might be expected.

Wednesday, Septemlier 25th. Morning IReting.

I). Deistaxcine in the Chair.

Prof. Kirchner (Wurzburg). a Casi of Sarcoma of the Petrous Bone.

The case was originally one of chronic suppurative inflammation of the middle ear, which eventually called for mastoid operation. When the process was opened it was found to be occupied by a tumour obviously of malignant nature, and a probe passed to the depth of five or six centimitres. I)eath occurred six weeks later, and it was found that the whole temporal bone was embedded in a growth of cheesy consistency from which it could be cut out by means of a knife without chisel or saw. Microscopically it was seen that the growth had originated in the mastoid cells, that it was a sarcoma, and that it had clevelopecl on a ground-work of chronic suppurative inflammation, as P'rof. kirchner had found in two previous calses.

P'rofs. FrRRFRI and GRAIENIGO and I)r. BRIICATR described similar cases.

1)r. Gritul: asked if the glands were affected.

I) Mocke mentioned two cases, in one of which facial palsy was absent entirely, and in the other until nearly the very encl.

Prof. Potriczer recalled a case published by him in which sarcoma, commencing in the mastoid, extended to the middle ear, then through the internal meatus to the brain.

1)r. Sunt: y MoL.ss had observed one in which the sarcoma, commencing externally, extended inwards to the cerebellum, and caused vẹtigo and facial paralysis.

Prof. KIRCINER replied that the glands were not affected.

Dr. THOMAs B.ARR ((ilasgow). Introduction to the Discussion on the Treatment of Intra-Cranial Abscisses following l'urulent Disease of the Middle Eiar.

We are able to reach and deal successfully with the following conditions:-

I. Abscess in the cerebrum, cspecially in the temporo-sphenoidal lobe.

2. Abscess in the cerebellum.

3. I'urulent formations at the base of the skull, either (a) between the 
bone and the dura mater ' the so-called extra-dural abscess), or ( $b$ ) between the dura mater and the surface of the brain (the sub-dural abscess).

4. Infective thrombosis of the sigmoid sinus even when secondary foci may exist elsewhere.

Preliminary Opening of the Middle Ear.-In many of these conditions we are able to reach the abscess most conveniently from the cavities of the middle ear; in others, we can deal with it more satisfactorily through a trephine opening in the lateral wall of the skull, above or behind the middle ear.

In all of these conditions it is essential, as a preliminary operation, to explore the cavities of the middle ear by removing the outer wall of the antrum. With the cavities of the middle ear thus opened, we ought to scrutinize with a good light and a reflecting mirror the bony partition which separates the tympanum and antrum at their roof from the dura mater, as well as (and this is perhaps more important still) the bony partition of the sigmoid groove. The existence of a carious aperture of an exposed dura mater or sigmoid sinus or of granulation tissue sprouting from these, will regulate our further procedure. The partitions of the roof and sigmoid groove, separating the middle ear from the temporo-sphenoidal lobe above, and from the sigmoid sinus behind, are without doubt the two great pathways by which the infective matter effects its fatal entrance to the interior of the cranium. Fortunately, they are both accessible, and readily accessible, from the middle ear spaces, and by the preliminary and essential operation of opening these spaces we are able to remove the pus, the cholesteatomatous matter, the granulation tissue, the carionecrotic débris, and the pathogenic organisms from the antrum and attic, these primary and dangerous formations (the "dynamite" of Prof. Macewan) which bring the patient's life into peril.

Modes of operating - The rotating bur. In the presence of symptoms pointing to abscess, meningitis or septic thrombosis, we must now from the middle-ear spaces boldly and without hesitation open these vulnerable and bony partitions and follow up the path of invasion. This is done with great safety and efficiency by means of the rotating bur propelled by a dental engine, supplemented by the use of a good sharp gouge. In exposing the cavities of the middle ear as well as in opening these lethal partitions, Dr. Barr now rarely uses the chisel and mallet, since Prof. Macewan directed attention to the globular dental bur which, with the help of gouge, he finds more safe and satisfactory than the chisel and mallet. $\quad$ The burs and temporal bones demonstrating their effects, both on the normal and diseased bone, exhibited.] In employing this method of breaking down bone it is very important to use burs which are very hard and sharp, and those made at Philadelphia are much the best. A dental engine of considerable power, worked with the foot, is required; the hand-piece is held like a pen, and the lateral part of the bur is applied to the bone, which, as the bur rapidly rotates, is raised in flakes. To prevent excessive heat developing, as well as to allow inspection of the parts, the bur should be momentarily removed every few seconds. It is possible with this instrument to avoid any structure in however close proximity it may be. As Prof. Macewan observes : "Dark apertures or 
"a membrane-such as a pyogenic membrane, or the sigmoid sinus, or dura "mater, are readily seen on the white-polished surface made with the bur." By this mode of operating, even although there be an abnormalty in the relative positions of the interior of the cranium to the midclle-ear spaces - such as unusual depth of the middle fossa (brachy-cephalic skulls) or an unusually anterior and outward position of the sigmoid fossa-the dura mater or lateral sinus need not be injured, although exposed. When we are working deep in the bone, and especially if the osscous tissue is soft, a sharp gouge yields effective aid, while a mirror on the forehead, reflecting good light into the deep cavity; is essential to safety. By simple and judicious extension of the operation for exposing the cavities of the middle ear, familiar to all of us, we can, in many cases of intracranial complication from purulent ear-disease, reach the scat of mischicf and deal satisfactorily and safely with it-and in all cases such cxposure of the middle ear (antrum and attic) with opening of the cranial septa should take place before proceeding to the use of the trephine.

Extra-Dural Abscess.-Having broken down the cranial partitions, we shall find, in a certain proportion of cases, pus between the clura mater and bone, the extra-dural abscess, in one or other of the vulnerable situations. Above the tegmen antri, or tegmen tympani, pus is often found extradurally, the removal of which, without going decper, brings about the disappearance of grave symptoms. Such extra-clural formations may be the precursors of temporo-sphenoidal abscess, just as similar formations at the sigmoid groove often lead to septic thrombosis of the lateral sinus, general septiciemia, or cerebellar abscess. Operations for the removal of extra-dural abscess have been singularly successful, and during the last seven years thirty-nine cases have been reported of extra-dural abscess, either at the tegmen or at the sigmoid groove, opcrated upon and followed by recovery.

Septic Thrombosis of Sigmoid Sinus.-Extra-dural abscess in the situation of the sigmoid groove is generally associated with septic thrombosis in the sigmoid sinus-hence in all such cases the sinus should be carefully examined. If it is found to be occupied, as it generally will, be by a thrombus, and if symptoms cxist pointing to disintegration of the clot and general septic infection, the blood current, if still flowing through the sinus, should be stopped in order to prevent further systemic infection. This is achiered either by ligature of the jugular vein in the neck, as first proposed by Victor Horslcy, or, as advocated by Macewan, slitting up the freely exposed sinus, removing the septic thrombus, stuffing with iodoform gauze, and by pressure bringing the outer wall of the sinus into contact with the inner, thus obliterating the venous tube. If there is reason to belicre that the sinus is quite occluded, and the circulation entirely checked, the simple application of antiseptics and pressure may suffice. In the hands of Victor Horsley, Arbuthnot Lane, Ballance, and others, the operation of ligaturing the jugular vein in two places and cutting between has proved very satisfactory, and there are now thirty-six recorded cases of successful operations where septic thrombosis and general infection cxisted.

Operating upon Intra-Dural Abscess. - Further exploration, by 
opening the dura mater at the tegmen of the middle ear or behind the sinus, will depend upon the symptoms, as well as the conditions, found present. In the presence of symptoms of lepto-meningitis, such extension of the operation may reveal purulent formations between the dura mater and brain in one or other of these localities, the removal of which may save the patient. No doubt the purulent exudation in such cases is generally too diffused to be susceptible of thorough removal, and these are certainly the least hopeful of all intra-cranial complications in ear disease, yet the experience of Prof. Macewan and others has shown that localized purulent collections in lepto-meningitis may be removed, with the result of saving the patient's life. If granulation tissue be seen protruding from the exposed dura mater, careful inspection should be made, when' a sinus may be found leading into the arachnoid cavity. The discovery of such a sinus would call for the free opening of the dura, and in the event of purulent formation, with perhaps ulceration or erosion of the surface of the brain being found, thorough cleansing and antiseptic treatment of the interior would give the patient a chance, as shown by the fact that sixteen cases of success are recorded of operations for the relief of purulent collections due to lepto-meningitis.

Cerebral or Cerebellar Abscess.-In the presence of symptoms pointing to abscess in the temporo-sphenoidal lobe, or in the cerebellum (and the diagnosis of an uncomplicated abscess in the temporo-sphenoidal lobe may be said now to belong to the region of certainty), no time should be lost before we open the abscess cavity by means of a canula and trocar or hollow needle, remove its contents, and, as far as possible, cleanse and disinfect the interior. In dealing efficiently with such abscesses in the temporo-sphenoidal lobe, or in the cerebellum, a trephine opening is required in the lateral part of the skull above the ear, or, in the case of the cerebellum, behind the sigmoid sinus. In the case of temporo-sphenoidal abscess, we might, no doubt, by simply increasing, with the bur in an outward direction, the size of the opening in the tegmen, reach, evacuate and drain the abscess very thoroughly, and such an enlarged opening it would be well to make in any case. Yet it is found that, in order to get rid of the sloughs of brain tissue, loaded with septic organisms, generally found in such abscesses, a trephine opening through the wall of the skull, of half an inch diameter, is also required in addition to the opening connected with the middle ear.

Mixed Cases of Intra-cranial Disease.-Prof. Macewan believes that " in uncomplicated abscess of the brain, operated on at a fairly early period, recovery ought to be the rule." I It is to be remembered, however, that many cases are of a mixed character. We often have abscess formation in the brain, with lepto- or pachy-meningitis, or with septic thrombosis of the lateral sinus, or the whole of these conditions may exist at the one time in the same patient. If lepto-meningitis exists along with abscess in the brain tissue, the symptoms of the latter are masked by those of the former, and we are apt to conclude that we have to deal with a pure meningitis, and decide against operation. My $x 893$.

1 Prof, Macewan in the work "Pyogenic Infective Diseases of the Brain and Spinal Cord," 
experience, however, would incline me to the view that although the symptoms may be those of lepto-meningitis, our duty is to expose the middle and posterior fossa of the skull, and search for pus. $A$ few wecks before leaving Glasgow, Ur. Harr had a case in point. A woman, twentyeight years of age, had suffered from a purulent disease of the right middle ear from early childhood. In the month of July she was scized with symptoms of intra-cranial mischief, there were vomiting, intense pain all over the head, rigors on three occanions, persistently clevated temperature, quick pulse, delirium with unceasing movement, and entire absence of sleep. In fourteen days from the apparent commencement of the intra-cranial mischicf, these symptoms terminated in death. Inmediately after sceing her for the first time, he opened the cavities of the middle ear with the bur, removed futid purulent matter and inflammatory débris, and also exposed the clura mater at the roof of the antrum, as well as the wall of the lateral sinus. (These openings were shown in the patient's temporal bone, illustrating also the efficiency of the bur.) There was no thrombosis of the sinus, and no pus between the clura mater and bone in either situation. As the symptoms did not scem to point to abscess in the brain, but rather to meningitis, he procecded no further. On examining the interior of the skull after death, while he found extensive lepto-meningitis on both sides with lymph and purulent deposit, there was likewise an abscess in the temporo-sphenoidal lobe, the pus from which had partially macle its way through two perforations in the base of the lobe into the middle and posterior fossa, and also into the spinal canal. From the thickness of the pyogenic membrane lining the abscess, there was reason to believe that the abscess had existed for a considerable time before the onset of the symptoms of intra-cranial mischief, and that the lepto-meningitis was really set up by the escape of the pus into the sub-dural space. While the trephining of the skull would not have saved this paticnt at the time she came under his observation, it would perhaps, from the surgical point of view, have been more satisfactory had the collection of pus been exposed, and drained as far as possible. It is even conccivable that, at a rery carly stage of the symptoms the meningitis might have been checked, and the patient's life saved by the thorough removal and drainage of the contents of the abscess, and the antiseptic treatment of the affected parts. 'The present trend of surgical opinion is therefore that we shall rarely go wrong if in the presence of grave intra-cranial symptoms, evidently due to a chronic septic process in the middle car, $1 \mathrm{c}$ cxplore the various pathways by which the disease invades the interior of the skull, and, if no extra-dural collection be found, or when found, if its removal be not followed by marked improvement, we open the dura mater, eximine the sub-dural space, and even then if the results be negative, we need not hesitate to explore the temporo-sphenoidal lobe or cercbellum, or both.

The record of work during the past seven years in the operations for cerebral and cerebellar abscess has becn remarkable. At least fifty-nine cases of cerebral abscess and seven cases of cerebellar have been successfully treated. Many of these were associated with septic thrombosis of the sigmoid sinus, some with meningritis. 
The Brilliant Results achieved.-In the various medical journals there have been reported, in the last seven years, records of one hundred and fifty-eight cases in which operations, followed by complete recovery, have been performed for the relief of the intra-cranial complications of purulent ear-disease. We are justified in believing that, in addition, there have been many unrecorded cases. Dr. Barr knew himself of some such cases. Our great aim and object should be to avert these dire results of purulent ear disease. By the enlightenment of the general public, through the fuller education of the profession in the gravity of those affections, by instructing the profession in the rational treatment of those affections, and by the development of those operative procedures calculated to remove hitherto intractable forms of purulent disease of the ear, we may in the future to a great extent prevent these intra-cranial complications. Indeed, the time will soon come, when, with few exceptions, every purulent affection of the ear will be within the curative resources of our art.

He offered the following questions for discussion :-

I. Is it desirable that the pure otologist should himself operate on the skull and brain in these intra-cranial complications of ear disease?

2. Should the interior of the cranium be opened even when the symptoms point to diffuse meningitis?

3. What is the best method of dealing with a thrombosed lateral sinus -ligaturing the internal jugular, or incision and pressure?

4. What is the best method of perforating the bone while opening the cavities of the middle ear, or the cranial septa of the middle ear?

5. The value of operative treatment on the cavities of the middle ear for the cure of intractabie purulent cases as preventive of intra-cranial abscesses.

Prof. GRADENigo (Turin) referred to the great progress that had been made in regard to the diagnosis of these affections and to the fixity of the "normals" for operative interference. He insisted on the necessity for the publication of all cases, both good and bad. Out of sixty-eight cases of aural disease calling for operation this year, twelve required intra-cranial measures. Two cases of cerebral abscess recovered and two of cerebellar abscess died. He thought the aurist should be the operator and that operation should be performed even in cases of meningitis. The diagnosis of sinus phlebitis or of cerebral abscess was always possible, that of cerebellar abscess was not. In operating, he considered it undesirable to use the mastoid opening to get at the inside of the skull.

Dr. URBAN PRITCHARD (London), in reply to the question as to whether the aurist should operate, gave it as his opinion that an operating surgeon should act with him. In case of supposed diffuse meningitis it was right to operate. As regards the instrument to employ, he had hitherto made use of the gouge, but he thought the burr was the instrument of the future.

Dr. Bobone (San Remo) described a case in which the symptoms called for opening of the mastoid, where nothing was found, and also of the sinus with the same result. Cerebral abscess was sought for and not found. Finally, on post-mortem examination, an abscess was found in the opposite cerebral hemisphere. 
Prof. Politzer remarked that in some cases there were marked symptoms with no abscess, and in others abscess with no symptoms. Sometimes there were two abscesses. Fixed pain as a symptom was sometimes deceptive. As regards results of operation, some which had been published as cures were not permanent. He knew one in which death took place two years later from a fresh abscess. The operative treatment of sinus phlebitis was most promising.

Dr. BRIEGER mentioned, as one step in advance, the lumbar puncture of the spinal canal for the detection of meningitis. If meningitis was thus detected, operation should be avoided. Operation when indicated should be carried out by the mastoid opening, but by means of an osteo-plastic flap which could be returned to its place if recuired. The prognosis should always be guarded. In one case of cerebral abscess successfully treated, death took place from cardiac failure five months later, without anything being found to account for it. Ile thought it was perhaps to be attributed to toxines. Even in cases of phlebitis of the cavernous sinus operation was possible, and in one case he had seen all the symptoms disappear after exploratory incision. In another casc with symptoms of cavernous sinusitis, the lateral sinus was operated on. After leath the cavernous sinus of the same side was empty, but the opposite one was occupied by an old clot. The lateral sinus of the original side contained an old clot within a recent one.

Dr. GORIS (Brussels) narrated a case of meningitis in which the disease was quite localized. In two other cases there were symptoms of meningitis; the patients were apparently moribund and could only be roused by loud shouting. After death no diffuse meningitis was found. He argued, therefore, for operation in spite of meningitic symptoms being present.

Dr. Morpurgo (Trieste) said the otologist ought to be able to carry out the whole series of operations, and expressed the opinion that many operating surgeons were unequal to the occasion. In private practice it was inevitable that operation was postponed longer than in hospitals, to the consequent detriment of the patient and to the chance of cure. He held that in all large towns there ought to be hospitals in which private cases, when acute and dangerous, could be treated operatively by the aurist.

Mr. BABER (Brighton) stated that this was the case in England.

Prof. GRADENIGO expressed his opinion that the aurist ought to be the operator. As a rule, he held that ligature of the jugular was not required, and that even an incision was unnecessary, unless there was evidence of sepsis. He maintained his opinion that cerebral abscesses should be reached directly through the cranium, and not through the tegmen tympani.

\section{Dr. Heymann (Warsaw). A Case of Cerebellar Abscess.}

This was the seventh case Dr. Heymann had had the opportunity of watching. It was that of a soldier, with meningitic symptoms-romiting, vertigo from right to left, perforation of the right tympanum, and preservation of bone-conduction. Hc made a diagnosis of cerebellar abscess, but the operator declined to carry his exploration beyond the tempero- 
sphenoidal lobe. Temporary improvement followed the exploration, but cough and bronchitis ensued, and the middle ear was cleared out. An antisyphilitic treatment was then insisted on, and some improvement as regards equilibrium ensued, but the headache persisted, although varying in position. The cerebellum was later explored (incompletely?), and no pus was found. Next morning the patient felt better, but he got weaker and died. On post-mortem examination the right lobe of the cerebellum was found full of pus. Dr. Heymann thought this abscess must have been in existence for two years.

\section{Dr. St. Clair Thomson (London). On Antiseptics in Intra-Nasal Surgery.}

The writer drew attention to the bacteriological investigations carried out by himself, along with Dr. Hewitt, with regard to the absence of bacteria in the nasal mucus beyond the vestibule, and also to the effect of any foreign body in causing an increased flow of bactericidal mucus, and in exciting ciliary action for its own expulsion. Chemical antiseptics in the nose were therefore unnecessary and injurious, and in nasal operation all that was required was the disinfection of the finger when introduced into the naso-pharynx, and the sterilization of the instrument in a one in twenty solution of carbolic acid. He considered the precautions recommended by Drs. Lermoyez and Helme as needlessly complex.

\section{Wednesday, September 25th. Afternoon Meeting.}

DISCUSSION ON DR. ST. CLAIR THOMSON'S PAPER.

Dr. HELME (Paris) said that the precautions referred to were really very simple, however complicated they might seem, and they were nothing more than was necessary to protect them against the criticisms of operating surgeons.

Prof. GRADENIGo (Turin) thought the difference between the normal and the diseased nose in relation to the bactericidal action of the nasal secretion was not sufficiently kept in view. They reacted very differently to galvanic cauterization. The main point to be attended to was the sterilization of instruments.

Dr. Bronner (Bradford) insisted that all instruments should be boiled, and that plugging the nose should be avoided.

Dr. BRIEGER (Breslau) said that only very small portions should be removed at a time, so as not to diminish too much the amount of surface secreting bactericidal mucus.

Mr. Cresswell BABEr (Brighton) considered it impossible to keep wounds in the nose aseptic; in cleansing he recommended a 0.7 per cent. solution of chloride of sodium.

Dr. Dundas Grant declined to be tied by a hard and fast rule with regard to irrigation and plugging. He strictly avoided plugging, except when necessitated by hæmorrhage, and he likewise avoided syringing, 
except when an accumulation of purulent secretion likely to afford a nidus for saprophytic, or even pathogenic, organisms called for its use. In such cases he employed a coarse spray or a douche with a very fine india-rubber tip, such as would allow free egress for the fluid.

Dr. DALY (Pittsburgh, U.S.A.) believed in rendering the parts aseptic before operation by thoroughly cleansing them and then spraying them with $\mathrm{a} \mathbf{I}$ in 5000 solution of corrosive sublimate. After the operation he introduced a platinum splint, covered with cotton-wool and moistened with a mixture of oil of eucalyptus (one part), oil of tar (one part) and compound tincture of benzoin (four parts), which he left in situ for a number of days.

Dr. ST. ClimR Thoxison pointed out that Drs. Lermoyez and Helme allowed that chemical antiseptics, such as a one per cent. solution of pheno-salyl, were sufficient for the sterilization of those instruments which would not stand boiling. He contended, therefore, that logically, if they were sufficient for some, they were sufficient for all. In regard to the question of plugging, a strong argument against it was the fact that the pathogenic microbes grew more readily when air was excluded.

Prof. Politzer. On the Pathological Changes which Occur in the Labyrinth. (Vide p. 795.)

This valuable communication contained a general account of the present state of knowledge as to the forms of disease to which the labyrinth was subject, and was illustrated by the records of cases, with the demonstration of the sections made after deatlr. The fullest descriptions were those of labyrinthine disease due to suppurative inflammation of the middle ear and to malignant disease inside the skull, the ossific changes and the narrowing of the vessels occurring in syphilis-the detection of Heubner's changes in the vessels of the labyrinth having been made by Kirchner. Tuberculosis primarily affecting the labyrinth had not yet been seen. Prof. Politzer had demonstrated last year at Rome the "chronic capsulitis" of the labyrinth, leading to obliteration of the fenestra ovalis, which occurred in sclerosis of the middle ear, and was clinically recognized as such. He was prepared to believe that in time the term "sclerosis of the middle ear" would give place to that of "chronic capsulitis."

Dr. Moure (Bordeaux). A Case of Aural Polypus, with Hamorrhage.

In this case the polypus was of ordinary appearance, but with a little granulation on its surface. On manipulation it gave vent to such a violent hæmorrhage that repeated plugging with iodoform gauze was necessary, and led to the question as to whether the bleeding might not arise from aneurism of the jugular vein. On complete removal the growth was found to be in part a cavernous angioma.

Dr. de Roaldes (New Orleans). A Preliminary Note on Certain Peculiarities of the Negro in Otology.

The writer's statistics showed that, as compared with the white races, the negroes were singularly free from sclerosis of the middle ear and from deafness in gencral. Among them the percentage of deaf-mutes was 
only half as large as among the whites. The nasal and naso-pharyngeal cavities were much wider, as also were the external auditory meatuses. There was, therefore, a relatively greater liability to the entrance of foreign bodies and insects.

Dr. MADEUF (Paris) asked if the negroes observed by Dr. de Roaldes slept on their backs on the ground. That attitude was favourable to the freeing of the naso-pharynx from nasal secretion.

Dr. Helme (Paris) inquired if they were subject to adenoids.

Mr. BABER drew attention to Catlin's observation that the American Indians were most particular to breathe through the nose only, and that they were singularly free from many diseases to which mouth-breathers were liable.

Dr. DE ROALDES replied that in towns the negroes lay just like Europeans, but that in the country it might be different. Adenoids occurred in negroes, but owing to the great capacity of the cavities their effects were seldom pronounced.

Dr. SUne y Molist (Barcelona). On Certain Peculiarities of Wounds from Firearms in the Mastoid Region.

The usual results are: firstly, the projectile fractures the bone into splinters ; secondly, the ball does not usually penetrate, and is easily extracted ; thirdly, the patient has signs of commotio cerebri. Before the healing of the wound the noises and deafness disappear. It is the structure of the temporal bone which prevents the penetration of the projectile, the petrous bone acting as a stout wall, while the flexible walls of the mastoid cells act as a soft cushion, and check the velocity of the projectile.

Dr. MORPURGO narrated a case in which the wound was followed by facial paralysis. A solid body was felt in the bottom of the opening, but there was great doubt as to its nature. The patient was unconscious for forty days. After between two or three months an abscess formed under the auricle, and on incision it was found to contain the bullet.

Prof. AvolEDo (Milan) referred to the medico-legal interest attaching to these cases in view of the distinction between suicidal cases and those homicidal ones in which the murderer pretends that the victim has shot himself.

Thursday, September 26th. Morning Meeting.

Prof. KirCHNER in the Chair.

Prof. Politzer (Vienna). Anatomical Demonstrations. Among other interesting preparations were a skull, showing the position of the membrana tympani and of the Eustachian tube. Two temporal bones with dehiscences in the squamous portion.

Also bones showing the openings produced in Stacke's, Schwartze's, and Koerner's operations. 
Prof. Masini (Genoa). The Influence of Lesions of the Organ of Hearing on Respiratory Changes.

Recognizing the probability from previous experiments that the irritation of one of the bulbar centres micht extend to those about it by radiation, the author, along with Dr. Polimant, thought the lesions of the auditory apparatus might influence certain of these centres. They commenced with the study of the respiratory centre, and came to the conclusions: (I) That in reality partial or total lesions of the organ of hearing could produce permanent functional disturbances in the bulbar centres. (2) That these disturbances are greater in case of partial than of total lesions. (3) That their intensity corresponds with the gravity of the disorders of equilibrium and of movement.

After the removal of the semi-circular canals in animals, there followed a loss of equilibrium in the elimination of carbon dioxide, which diminished. On the other hand, lesions of the cochlea could not be shown to have any influence upon the elimination of this gas.

Dr. Chivcini (Rome). A Mithod of Anatomical Section of the Temforal Bone, with Demonstration.

The sections were made in various directions so as to exhibit with the utmost ease the various parts of the temporal bone, and the important osseous structures and relations of the organ of hearing. The portions were fastened together by means of delicate hinges, so that they could be opened out and closed together again like the leaves of a book.

Mr. Cresswell Baber (Brighton). Phantoms for the Study of Postnasal Palpation.

By means of these, the student may rapidly acquaint himsclf with the digital topography of the posterior nares, and get a very fair idea of the "feel" of the parts in health and diseasc. Ear.

Dr. Carlo SeCchi (Bologna). On the Physiology of the Middle

The author referred to views he had previously expressed with regard to the intra-tympanic pressure, which he held to be higher than the atmospheric. He considers the tympanum to act like a Marey's tambour-a capsule filled with air, which, expanding equally in all directions in obedience to Pascal's law when compressed from without, communicated vibrations to the fenesta rotunda primarily. The ossicular chain had not been proved to be the conductors of sound, and their function was of only secondary importance-namely, as a mechanism of accommodation. By means of a manoneter in connection with the cavity of the middle ear of a $\log$, he demonstrated a rise of intra-tympanic pressure under the stimulus of a whistle or other sound.

Dr. MoNG.1Rur (Bologna) held that Dr. Secchis opinion that the ossicles took no part in the conduction of sound was incorrect, in view of Auller's experiments repeated by himself, in which an artificial tympanic apparatus without ossicles was found to conduct very imperfectly when compared with what it dicl when ossicles were adapted to it. 
Dr. GELLÉ protested against the rash interpretation of observations on a moribund dog in a sense opposed to the views regarding the ossicles so long held and so strongly confirmed by clinical and other facts.

Dr. Dundas Grant considered, as an argument against the uncompromising acceptance of Dr. Secchi's view that the tympanum acted as a tambour, the very fair degree of hearing often existing in spite of the presence of a perforation when the "air-capsule" action must be impossible and conduction must, in great measure at least, take place through the chain of ossicles. On the other hand, he thought there was much in favour of Dr. Secchi's contention that the intra-tympanic pressure was greater than that of the atmospheric, and cited an instance in which he saw a cicatrix bulge out distinctly during deglutition. This did not prove that swallowing always caused a distension of the tympanum, but it proved that it could do so, although the opposite effect was much more frequently observed. There was, in his opinion, a good deal still unknown with regard to the physiology of the middle ear.

Prof. Politzer considered the ossicles the primary means for the conduction of sound vibrations, and the intra-tympanic air and fenestra rotunda only secondary. He considered experiments on the cadaver extremely valuable.

Prof. Gradenigo expressed his admiration for the industry and skill with which Dr. Secchi had worked out the experimental evidence in support of his views.

Dr. SECCHI repeated his conviction that in time his views would receive acceptance, and that at present there were some gaps in our knowledge of the functions of the middle ear.

Dr. A. D'Aguanno (Palermo). On the Paracusis of Willis.

In general Dr. D'Aguanno held that the conditions which brought about this symptom were relaxation of the ligaments or degeneration of the muscles of the tympanic ossicles.

Dr. Verdos (Barcelona). Aural Disturbances resulting from Explosions of Dynamite.

The dynamite outrage in the Lyceum Theatre of Barcelona gave the writer the opportunity of studying the effects on the ear. He did not observe hæmorrhage from laceration of the tympanum, such as takes place from the firing of big guns. On the other hand, in those who were close to the bomb there was a violent hyperæmia of the auricle and of the temporo-mastoid region, the external meatus and the external surface of the membrana tympani, with propagation to the tympanic cavity. In four or five days the patients were perfectly well, and in all of them the lesion was unliteral. In none was there a perforation of the tympanum. In those who were at some distance there was no hyperæmia, but a distinct depression of the tympanum with tinnitus and slight vertigo. In them a recovery did not occur till from two to three weeks, and their lesions were bilateral. Those who were in the higher boxes of the theatre had labyrinthine symptoms which could not be ascribed to hyperamia, but probably to an irritation of the acoustic nerves. A few experi- 
enced some disturbance in their sense of position, which the writer attributed to inhibition of the functions of the auditory nerre.

Dr. LUBET-BARHON (Paris). The Localization of Infammation of the Temporal Bones in Relation to the Development of these Bun's.

The writer held that the inflammatory discase-especially when spontaneous-tencled to limit itsclf to one or other of the segments of which the temporal bone was made up. Thus clisease of the petro-mastoid portion did not extend above the temporal line, that of the sejumous portion affected only the upper wall of the meatus, that of the tympanic portion expressed itself in necrosis of the postcro-inferior portion of the meatus.

Prof. GRAJlini(io (Turin). On the Functional Examination of the Hearing Power.

In view of the diannostic value of the measurement of the hearingr for notes in the different parts of the range, and of the auditory-lield as tested by Zwaardemacher and by himself, l'rof. (iradenigo solight a ready mechanism for this purpose. l'ure tones were necessaly, and they could only be elicited from tuning-forks. The difficulty with them was to get a constant initial intensity and spring-hammers did not enable us to effect this. He therefore had each tuning. fork mounted on a frame and adapted to it an apparatus like a fork which compressed the blacles together. The lifting off of this ailowed them to expand with a definite degree of force, and consequently to start vibrating with a constant intensity. Four degrees of compression could be effected so that four, degrees of intensity of tone could be produced. According to the degree required for the patient to hear it, the hearing power could be measured sufficiently near for all practical requirements, and the amount could be very simply expressed in numbers.

Dr. Dundas GRaN'T expressed his indebtedness to Prof. Cradenigo's writings for his appreciation of the value of tests for the hearing of toncs in different parts of the scale. He thought the mechanism derised by Prof. Gradenigo would remove tlie difficulty they had all felt. The method originally practised by the professor, like that of Hartmann, consisted in placing the number of scconds the patient hears the fork as a numerator, and as a clenominator the number it is heard by a normal person. If this is reduced to a percentage it can easily be shown that the values will vary according as the length of time of hearing by a normal person varies with the force of the blow. I)r. (irant sugrgested that Prof. Gradenigo's appliance could be regulated so that normally the fork should be heard at a difinite aistance. The distance at which the patient could hear might then be noted, and a ratio readily obtained in which the fallacy above mentioned was aroided.

Prof. Politzer contended that the voice was the only test of practical value, and that all the other tests in use frequently gave totally different results from the vocal one.

Prof. GRADENIGO held that as the voice only covered from two to three octaves, it was necessary to make use of the more extensive scale afforded by the tuning-forks. 


\author{
Dr. Silismund Szenes (Buda-Pesth). On Traumatic Lesions of \\ the Organs of Hearing. \\ Notes of this paper will appear later.
}

Prof. BARgeldin'. Remarks on Therapeutic Points derived from a long experience.

(Now, in the eighty-sixth year of his age, this doyen of Italian otology was a frequent attendant at the mectings of the Congress, where he received from his younger confrites and pupils the deferential owation to which his fame entitled him, and which the sight of his striking and venerable appearance croked.)

Among other contributions from his experience, he particularly dwelt on the value of local depletion by means of leeches, a mode of treatment of which he considered that the present generation of aurists made ton little use.

I'rof. V. (ikazzI (Florence). A Case of Complete Deafness followiting Acut Weningitis with the Liplococus of Fraenkel.

In this case the patient, a young woman, had a fererish attack, which was attributed to diphtheria, but in which the secretion contained only Fracnkel's diplococcus. Well-marked symptoms of meningitis and complete deafness ensued. In two months she lost her memory for words, and became quite mute. l'ilocarpin treatment was employed, but without avail.

Dr. CORR.1DI (Verona) had seen benefit follow the use of pilocarpin in syphilitic cases.

Prof. GRADENicio alluded to the great difficulty in distinguishing abortive meningitis from inflammation of the labyrinth.

Thursday, September 26th. Afternoon Mecting.

Dr. Morrevkio in the Chair.

Dr. Adotph Bronner (Bradford). Local Massage in the Treatmont of Chronic Eczema of the Exteral Ear.

Dr. Bronner had found this process successful in several cases, in which ordinary treatment had proved useless. The vibration may be produced by the hand, or by a machine (trcadle or electro-motor). A thick silver probe is employed, with cotton wool twisted round the tip, smeared with a mercurial ointment. The vibrations should be rapid, about seven hundred per minute, continued for from one to five minutes. This has to be repeated daily till the skin is red and swollen, when it has to be omitted for a few days. As a rule, six or seven sittings are required.

In reply to Dr. D.ALY he stated that the ointment he employed was yellow oxide of mercury, wr. $\mathrm{x}$ ad. $\mathrm{z}$ j.

Dr. D.1.y (I'ittulursh) saicl he had had great success, even in obstinate 
cases, with the following ointment :-Hyclars, ammon.-chlor. : hydrarg, sub-chlor., à gr. j. ; "cold cre.m" j]. "To atroid hilure it should not be applied to a dry skin.

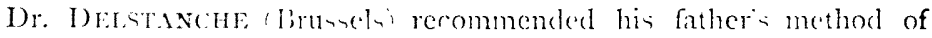
treatment, consistingr of free wahling of the part with atectate of learl dissolved in distilled water, followed by vigorous friction with the thumb and finger.

Mr. CResswell bime asked if the massage was beneficial in seborrhesa, and I)r. BRANVIR replied that the best treatment was the use of nitrate of silver.

Dr. BRIAER (Breslat incommented the une of tampons retained for a long time.

Dr. V.GAkzia (Naples!. I. On the Influence of Syphilis in cortain Affections of the Ear. 2. Produnculated Frostisis of the External Miatus.

(Communicated for publication though not rearl.)

Dr. Madeur (Paris). On Affietions of the Mitlle Ear in Mammals.

This communication wat not reatl.

Dr. DeLstaxche (Brusich)! Dimonstration of Instruments.

An interesting account of 1$)$ r. I) lutanche's vell-known appliances.

The Closing Ceremonies tork plare in the Aula Maxima in the presence of several imporams repre-entative of the Authoritien. The

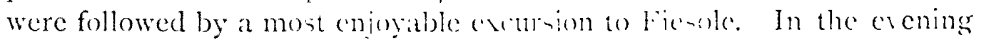
the P'resident took the (hair at a manitisent banpuet, to which were invited all the foreign momber of the consten and their ladien, as

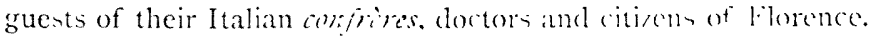

The generous hospitality offered on this occasion will not be forgotten in 1899 , when the nevt International congress meets in London.

\section{SIXTH ANNUAL MEETING of the BELGIAN OTOLOGISTS AND LARYNGOLOGISTS.}

Helit at Erussils, June I6th, iS95.

President-Dr. HI' (ritur (of the Polyclinic of Brussch).

Tre morning sitting was deroted to the presentation of patients and instruments, with demonstration of anatomical specimens.

Dr. CAP.ART showed an Adencid Tummer and ta'o Tonsils remarkable for their size, which he had remored by electrocal means. Rouneaus 